\title{
ORDERED FUZZY NUMBERS APPROACH TO AN INVESTMENT PROJECT EVALUATION
}

\author{
W. Konrad Kosiński ${ }^{1}$, Witold Kosiński ${ }^{1,2}$, Kacper Kościeński ${ }^{1}$ \\ ${ }^{1}$ Polish-Japanese Institute of Information Technology, Department of Computer Science, Poland \\ ${ }^{2}$ Kazimierz-Wielki University, Institute of Mechanics and Applied Computer Science, Poland \\ Corresponding author: \\ Witold Kosiński \\ Polish-Japanese Institute of Information Technology \\ Department of Computer Science \\ Koszykowa 86, 02-008 Warsaw, Poland \\ phone: +48 22 5844513 \\ e-mail: wkos@pjwstk(ukw).edu.pl
}

Received: 3 May 2013

Accepted: 10 June 2013

\begin{abstract}
Aim of the paper is to propose a new tool for a decision supporting system concerning the financial project evaluation. It is based on the determination of the internal rate of return (IRR) of a investment project in which all expenditure and anticipated incomes are vague, and described by Ordered Fuzzy Numbers (OFNs). It means that the probabilistic approach is neglected in this paper and the use of the well developed arithmetics of OFNs is made to find a positive fuzzy root of a fuzzy polynomial representing the fuzzy net present value of the project. Since in the space of OFNs a partial order relation is defined together with a number of defuzzification functionals, the authors can construct a decision support system for investors helping them in acceptance procedure of most profitable investment projects.

KEYWORDS

internal rate of return (IRR), net present value (NPV), Ordered Fuzzy Number (OFN), root of fuzzy polynomial, defuzzification functional.
\end{abstract}

\section{Introduction}

An increasing role of small and medium enterprizes requires new tools for supporting their activities in the nowadays economics. Especially when decision makers are planning new productions or investments. Moreover, it is hard to disagree with opinion that among all different investors' activities, the economical planning is very sensitive to the financial market which is the most uncertain. The main reason is the fact that huge amount of information is reflected in the financial market, and everything that happens in the world has an effect on quotations of financial instruments. On the other hand, how the information influence the market is decided by investors by taking a long or short position in the market. In each decision the maker has to find a reasonable compromise between the profitability and the risk. The profitability can be estimated on the base of the the investment rate of return. The es- timation is based on several variables: some of them are nominal and other numerical. However, in reality many economic variables are difficult to be measured with precision. Hence in present models, often, numerical decision variables are not expressed by real numbers or integers: they are expressed in a vague way, for example as fuzzy numbers.

When a decision-maker has to compare mutually exclusive investment projects he has for his disposal the method based on the internal rate of return (IRR). In the projects future returns and possible expenditures appear. However, future returns, already are always uncertain and a possible model of this uncertainty is to use fuzzy numbers.

It was Buckley, who in his first paper [1] on the subject of fuzzy internal rate of return used triangular fuzzy numbers to present net cash flow of a proposed investment project over $n$ periods of time. Employing traditional algebra and $\alpha$-cuts $[2-7]$ he argued in [1] that too often the fuzzy equation deter- 
mining a fuzzy internal rate of return has no solution: it exists if extra conditions on forms of the triangular fuzzy numbers are imposed. Then in the next paper [8] the new solution procedure for solving fuzzy equations was applied. In that case he showed that a fuzzy solution to the fuzzy equation exists, under rather weak assumption that the zero term in cash flow (the term modelling the initial expenditure) is negative and all the rest are positive. However, its support may be very large but contained in the interval $(-1, \infty)$.

To solve the fuzzy equation determining a fuzzy internal rate of return and to model imprecise term different method may be use from that in $[1,8]$. Another method to model imprecise terms are Ordered Fuzzy Numbers (OFN). In this paper we confine our interest to propose tools to a decision supporting system when OFN appear. It will be a system for investors which helps them in the process of selection of business plan in the case of imprecise data concerning expenditures and the future cash flows modeled using OFN. Thanks to well-defined arithmetic defined of OFN, it allows modeling uncertainty associated with financial data and constructing a full decision support system in future.

The organization of the paper is as follows. Section 2 is dedicated to problem of estimation of investment projects. It contains the main definitions of discounted values of cash flows, net present value and internal rate of return. Then the problem of the determination of the internal rate of return is formulated when cash flows are given as a problem of finding a positive root of a polynomial of given degree. In Sec. 3 the main problem is formulated for the case of crisp cash flows. The main definitions and operations on the set OFN are given in Sec. 4 . Here a class of real-valued functionals defined on the space of OFN is also introduced. Its elements, called defuzzification operators (functionals) are helpful in the final decision of the investors. In Sec. 5 the case of vague cash flows is considered. We are neglecting the probabilistic approach and the problem in terms of a polynomial with coefficients represented by step ordered fuzzy numbers is formulated. The natural conditions imposed on all fuzzy cash flows guaranties the existence of a root which is a positive ordered fuzzy number. Then numerical example is considered, where a 10 year investment project with fuzzy cash flows is elaborated. Different variants of orientations of OFNs are listed and fuzzy IRRs are calculated. Then 4 different defuzzification functionals are imposed on fuzzy rate. Two tools useful for a decision support system are constructed and final remarks and conclusions are contained in Sec. 6.
We should add that the fuzzy equation determining a fuzzy internal rate of return has been already investigated in the class of OFN with continuous branches in the paper [9]. On the other hand in the recent joint publication of the second author [10] the class of Rational Ordered Fuzzy Numbers has been used to model the cash flow. Then the existence of a fuzzy solution for IRR's equation has been proved based on the classical result of the algebra: the root of a polynomial is a continuous function of the polynomial coefficients.

\section{Investment project evaluation}

One of the ways of evaluating an investment project is to compare anticipated expenditures with the financial and others benefits which the company expects to achieve. These benefits may be presented with solid numbers but the matter of time is also crucial, especially when concerning long-time projects. This kind of difficulties and strong practical demand for solving methods are the purposes for which the rating and investment evaluation issue is widely studied [11-13].

Most of the rating and pick up investment methods are considered on ground of data which are the now-known information of the project. The project will last for a few years so for the projection we assume a whole number of years. Moreover, the expenditures and benefits are counted as for the end of period (in this case - end of the year). For the investment project evaluation the following data are essential:

- $n$ - the number (natural number) of years which will be length of the investment project,

- $W_{i}, i=1,2, . ., n-1$ - anticipated incomes, e.g. the benefits generated in successive years and calculated at the end of $i$-th year,

- $K_{i}, i=0,1,2, \ldots, n-1$ - anticipated project expenditures borne at the end of the $i$-th year for $i>0$, and $W_{0}$ expenditure at the beginning of the project,

- $r>0$ - annual discount rate used for discounting project incomes and expenditures, so-called cash inflows and cash outflows to the day 0 , the first year of the life of project.

If one defines the cash flow $a_{i}$ at the end of the $i$-th year as a dependence

$$
\begin{gathered}
a_{i}=W_{i}-K_{i}, \quad i=1,2, \ldots, n, \\
\text { and } a_{0}=-W_{0},
\end{gathered}
$$

then cash flows may be positive or negative but the cash flow $a_{0}$ is always negative. Using the discount 
rate $r$ for the cash flow $a_{i}$ the discounted cash flow equals to $\bar{a}_{i}:=\frac{a_{i}}{(1+r)^{i}}$.

Every business needs an initial analysis of aims and gains. Analysis like this is a part of a business plan, which is prepared in a several scenarios. These scenarios vary in the greatness of anticipated cash flows, the choice of an optimal scenario by the decision-maker (entrepreneur) depends on a few criteria. The discount rate is essential for this phase because one the base of discounted cash flows the decisions are made. The exact estimation of the discount rate is complicated and there are some opinions that in nowadays economy it is impossible. The discount rate depends on many economic factors, e.g. inflation, deposit interest rate, return on alternative investment and the credit interest rate. That is why the fuzzy numbers are so useful in estimating the value of the discount rate [14-16].

The profitability is one of the decision making factors. The measure of the profitability is the investment return rate. If we sum up all cash flow counted not in nominal value but in monetary unit at the day zero, that is at the beginning of the project, we obtain a value

$$
\sum_{i=0}^{n-1} \bar{a}_{i}=\mathrm{NPV}
$$

which is called net present value of the project $(\mathrm{NPV})$. Of course this valuation is done with the discount rate $r$, which means $\operatorname{NPV}(r)$. We consider positive NPVs because positive value of NPV means that the discounted cash inflows are higher than discounted cash outflows. In order to compare several projects or their scenarios it is assumed that the NPV $(r)=0$. The discount rate for which the NPV equals to 0 is called the internal rate of return abbreviated to IRR. This can be phrased in other words: the present value of all future returns must equal the initial outlay $\left(a_{0}<0\right)$ at the IRR which equals the unique solution $r$.

\section{Probability versus fuzzy approach}

Internal rate of return is determined by annual discounted cash flows in time of project duration. To calculate this return rate one needs to search the root of the polynomial of the degree equal to the project duration diminished by 1 . The differences in particular cash flow may be caused by not accurate estimates by the author of the business plan. These inaccurate done estimates may be characterized by the use of calculus of probability. We do not use statistical approach but the well-developed mathematical tool of Ordered Fuzzy Numbers developed by one of the authors (W.K.) and his two co-workers: Piotr Prokopowicz and Dominik Ślęzak in a number of papers [17-22].

As it was already stated by the author of [23] for many years the only tool representing imprecise and vague notions was the probability theory. Hence every suggestion to substitute this tool by the approach related to fuzzy logic and fuzzy sets leads to the question: is it worth to do this, and if yes then why? In the present paper we will focus our fuzzy approach on applications to economical problems, for which modelling the influence of imprecise quantities and preferences on decision maker's opinions is important. With the help of a fuzzy number it is possible to express incomplete knowledge about a quantity giving the possible intervals of its realization, and writing it in the form of a (subjective) function of the information, representing the capability degree of this realization. In this case only one condition appears, namely capability degrees may attain values from the interval $[0,1]$. On the other hand one may use a random variable, but in that case, however, we are forced to give the probability distribution (even it is subjective) of the quantity. Then we have to fulfil some constraint which follows from the definition of the probability. In the case of fuzzy numbers, on the other hand, the decision maker is completely free as far as the forms of the realization functions of the imprecise quantity are concerned.

\section{Problem statement}

Each investment project can be characterized by the series of cash flow. For the investment one forms a forecast of the cash flow for a number of future years. The flows contain perspective expenditures as well some benefits, i.e. anticipated incomes. Then the net cash flows are discounted at the initial year, i.e. the beginning of the investment project, and summed up to get NPV (Net Present Value). To calculate the discounted flows one must use a discount rate. Its value must be fixed for the time of the project duration. However, the question is how big it should be, and what to do when different business plans are to compare?

\section{Internal rate of return}

In a firm acting on the free market the internal rate of return knowing IRR of the investment project the investor can uniquely states whether its project meets the profitability threshold.

Let a given, or estimated, net cash flow of a proposed investment project over $n$ periods of time be represented by the finite sequence $a_{0}, a_{1}, a_{2}, \ldots, a_{n-1}$ 
of values, where $a_{0}$ is the initial outlay taken with the negative sign. Let us make the obvious assumptions: 1. Sum of all cash flow contributions must be positive.

2. The value of $-a_{0}$ is positive.

If we denote by $r$ the annual discount (return) rate then for each $k=0,1,2, \ldots, n-1$ the number $\left(\frac{1}{1+r}\right)^{k}$ is called the discount coefficient, and the product

$$
a_{k}\left(\frac{1}{1+r}\right)^{k}:=\bar{a}_{k}
$$

is called the discounted flow of $a_{k}$ in the $k$-th year. Then the sum of discounted flow contribution after $n-1$-st year under return rate $r$, denoted by $S(n, r)$, will be

$$
S(n, r)=\sum_{k=0}^{n-1} a_{k}\left(\frac{1}{1+r}\right)^{k} .
$$

If we introduce $x$ by the relation

$$
x=\frac{1}{1+r},
$$

then (3) we may write as a polynomial $W_{n}$ of variable $x$

$$
W_{n}(x)=\sum_{k=0}^{n-1} a_{k} x^{k} .
$$

Then the condition 1 of our assumptions means

$$
W_{n}(1)>0,
$$

while the condition 2 reads

$$
W_{n}(0)<0,
$$

since $W_{n}(0)=a_{0}$.

From these two constrains imposed on the polynomial values as a continuous function of $x \in \mathbf{R}$ and the Darboux property follows that in the open interval $(0,1)$ there exists an argument, denoted here by $x_{0}$, at which the polynomial value is zero

$$
W_{n}\left(x_{0}\right)=0 .
$$

Since the vanishing value of the polynomial correspond to the vanishing Net Present Value, it follows that there exists an internal rate of return $r_{0}$, given by the relationship: $r_{0}=\frac{1}{x_{0}}-1$.

We are interested in the investment projects that possess a sufficiently large IRR, say not less than a limit rate $r_{c}$. After introducing $x_{c}:=\frac{1}{1+r_{c}}$, we may say that we prefer such cash flows for which the corresponding value of the polynomial $W_{n}$ satisfies the condition $W_{n}\left(x_{c}\right)>0$. This means that the positive root $x_{0}$ will be not only smaller than 1 but also less than $x_{c}$.
In what follows will consider more general case, when the cash flows are represented by fuzzy numbers, then the polynomial values will be fuzzy as well as its root. Then the calculated IRR will be fuzzy and one of the acceptance criterions of given investment project with that fuzzy cash flow will be based on the comparison of the defuzzified IRR with the limit rate $r_{c}$.

The investment projects that are passing this criterion will appear on the list of advised projects. While the investment projects for which their defuzzified IRR do not overcome the limit rate $r_{c}$ will be neglected. In this way we are able to build a decision supporting system for investors estimating different business plans and projects. Additionally, we may use the (partial) order relation existing in the space of Ordered Fuzzy Numbers (OFN) in ranking (better to say - sorting) all projects, from the highest to the lowest according to their fuzzy IRR values, without referring to any defuzzification method.

\section{Ordered Fuzzy Numbers}

The definition of OFN uses the extension of the parametric representation of convex fuzzy numbers. Proposed recently by the second author and his two coworkers: P. Prokopowicz and D. Ślȩzak [17-21,24] an extended model of convex fuzzy numbers [25] (CFN), called Ordered Fuzzy Numbers (OFN), does not require any existence of membership functions. In this model we can see an extension of CFN - model, when one takes a parametric representation of fuzzy numbers which is known since 1986, [26] for convex fuzzy numbers. Our 'new' fuzzy number $A$ is identified with a pair of functions defined on the interval $[0,1]$, i.e.

Definition 1. By an Ordered Fuzzy Number A we mean an ordered pair $(f, g)$ of functions such that $f, g:[0,1] \rightarrow \mathbf{R}$ are continuous.

Notice, however, that in our definition we do not require that two continuous functions $f$ and $g$, called branches of $A$, are inverse functions of some membership function. Moreover, in generale corresponding membership function needs not to exist.

To be in agreement with further and classical denotations of fuzzy sets (numbers), the independent variable of the both functions $f$ and $g$ is denoted by $y$ (or $s$ ), and the values of them by $x$. The continuity of both parts implies their images are bounded intervals, say $U P$ and $D O W N$, respectively (Fig. 2a). We have used symbols to mark boundaries for $U P=\left[l_{A}, 1_{A}^{-}\right]$and for $D O W N=\left[1_{A}^{+}, p_{A}\right]$. 
If we assume, additionally, that 1) $f$ is increasing, and $g$ is decreasing, and such that 2) $f \leq g$ (pointwise), we may define the membership function $\mu(x)=f^{-1}(x)$, if $x \in[f(0), f(1)]=\left[l_{A}, 1_{A}^{-}\right]$, and $\mu(x)=g^{-1}(x)$, if $x \in[g(1), g(0)]=\left[1_{A}^{+}, p_{A}\right]$ and $\mu(x)=1$ when $x \in\left[1_{A}^{-}, 1_{A}^{+}\right]$.

In this way we have obtained the membership function $\mu(x), x \in \mathbf{R}$. When the functions $f$ and/or $g$ are not invertible or the condition 2) is not satisfied then in the plane $x-y$ the membership curve (or relation) can be defined, composed of the graphs of $f$ and $g$ and the line $y=1$ over the core $\{x \in[f(1), g(1)]\}$. Notice that in general $f(1)$ needs not be less than $g(1)$. In this way we can reach improper intervals for $\left[l_{A}, 1_{A}^{-}\right]$or $\left[1_{A}^{+}, p_{A}\right]$ which have been already discussed in the framework of the extended interval arithmetic by Kaucher in [27].

It is worthwhile to point out at this place that a large class of Ordered Fuzzy Numbers (OFN's) represents the whole class of convex fuzzy numbers ( $[2,3,25,28-30])$ with continuous membership functions.

In Fig. 1c to the ordered pair of two continuous functions, here just two affine functions, corresponds a membership function of a convex fuzzy number with an extra arrow which denotes the orientation of the closed curve formed below.

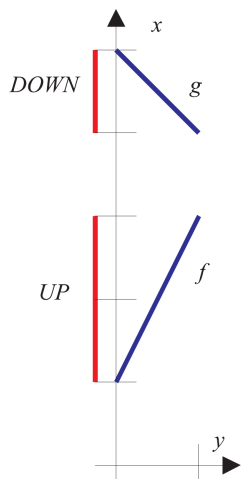

a)

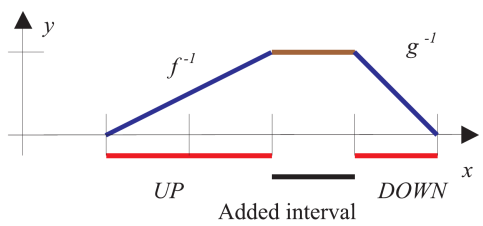

b)

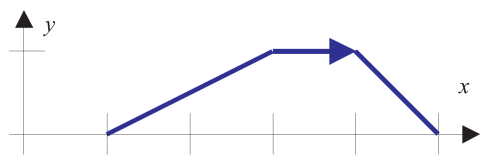

c)
Fig. 1. a) Ordered Fuzzy Number, b) Membership function of Ordered Fuzzy Number, c) Arrow denotes the order of inverted functions and the orientation

A pair of continuous functions $(g, f)$ determine different Ordered Fuzzy Number than the pair $(f, g)$; graphically the corresponding curves determine two different orientations of 2 ordered fuzzy numbers.

Notice that if some of the conditions 1) or 2) for $f$ and $g$ formulated above are not satisfied the construction of the classical membership function is not possible. However, in the previous paper [31] Prokopowicz has introduced the 'correspond- ing' membership function. The original definition of the Ordered Fuzzy Numbers [17] has been recently generalized in [32] by admitting for the pair $(f, g)$ to be functions of bounded variation (see Definition 5).

\section{Operations}

Now, the operation of addition between two pairs of such functions is defined as the pairwise addition of their elements, i.e. if $\left(f_{1}, g_{1}\right)$ and $\left(f_{2}, g_{2}\right)$ are two fuzzy numbers, then $\left(f_{1}+f_{2}, g_{1}+g_{2}\right)$ will be just their sum. As long as we are adding Ordered Fuzzy Numbers which possess their classical membership functions, and moreover, are of the same orientation, the results of addition is in agrement with the $\alpha$-cut and interval arithmetic. However, this does not hold, in general, if the numbers have opposite orientations, for the result of addition may lead to improper intervals as it was noticed already in [20] like in Fig. 2. In this way we are close to the Kaucher arithmetic [27] with (improper) directed intervals, i.e. such $[n, m]$ where $n$ may be greater than $m$.

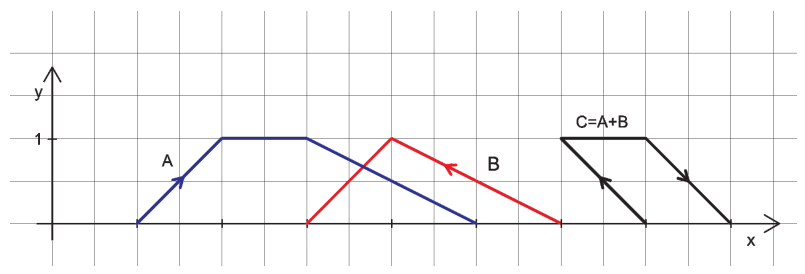

Fig. 2. Sum of two convex OFN's is an improper convex number

Definition 2. Let $A=\left(f_{A}, g_{A}\right), B=\left(f_{B}, g_{B}\right)$ and $C=\left(f_{C}, g_{C}\right)$ are mathematical objects called Ordered Fuzzy Numbers. The sum $C=A+B$, subtraction $C=A-B$, product $C=A \cdot B$, and division $C=A \div B$ are defined by formula

$$
f_{C}(y)=f_{A}(y) \star f_{B}(y) \quad g_{A}(y) \star g_{B}(y),
$$

where "*” works for "+", "-", ".", and " $\div$ ", respectively, and $A \div B$ is defined, if the functions $\left|f_{B}\right|$ and $\left|g_{B}\right|$ are bigger than zero.

If for any pair of affine functions $(f, g)$ of $y \in[0,1]$ we form a tread of real numbers according to the rule $[f(0), f(1), g(1), g(0)]$ which correspond to the a $4 \mathrm{D}$ vector composed of the numbers $l_{A}, 1_{A}^{-}, 1_{A}^{+}, p_{A}$, then this tread uniquely determines the Ordered Fuzzy Number $A$. In the assumed definitions the operation of subtraction is compatible with the linear structure of OFN's, i.e. $A-B:=A+(-1) B$. However, the present operation of subtraction is not the same as that based on the $\alpha$-cut and interval arithmetic method, since now $D[\alpha]=\left[a_{1}(\alpha)-b_{1}(\alpha), a_{2}(\alpha)-\right.$ $\left.b_{2}(\alpha)\right], \alpha \in[0,1]$. Thanks to this definition we will have $A-A=0$, where 0 is the crisp zero. 
If we attached to $A=(f, g)$ the corresponding number of the opposite orientation $A^{\perp}=(g, f)$ then we can see that the difference between them is a fuzzy zero, i.e. $A-A^{\perp}=(f-g,-(f-g))$ like for the fuzzy arithmetic based on both: extension principle and $\alpha$-cut arithmetics. For better presentation of the advantages OFN's notice in Fig. 2 that we can follow the operation of addition using the tread representation of two Trapezoidal Ordered Fuzzy Numbers of the opposite orientations, namely on this figure $C=A+B$ is $[7,6,7,8]$ and it is a sum of $[1,2,3,5]+[6,4,4,3]$ with $A=[1,2,3,5]$ and $B=[6,4,4,3]$.

Many operations can be defined in this way, suitable for the pairs of functions. Fuzzy Calculator has been already created as a calculation tool, by our co-worker Mr. Roman Koleśnik [24]. It lets an easy future use of all mathematical objects described as Ordered Fuzzy Numbers.

\section{Normed structure and defuzzification of OFN's}

Let $\mathcal{R}$ be a universe of all OFN's. This set is composed of all pairs of continuous functions defined on the closed interval $I=[0,1]$ and is isomorphic to $C([0,1]) \times C([0,1])$ the linear space of real $2 \mathrm{D}$-vector valued functions defined on the unit interval $I$ with the norm of $\mathcal{R}$ as follows

$$
\|A\|=\max \left(\sup _{s \in I}\left|f_{A}(s)\right|, \sup _{s \in I}\left|g_{A}(s)\right|\right)
$$

if $A=\left(f_{A}, g_{A}\right)$, with $C([0,1])$ as the space of continuous real-valued functions on $[0,1]$. The space $\mathcal{R}$ is topologically a Banach space and also a Banach algebra with unity: the multiplication has a neutral element - the pair of two constant functions equal to one, i.e. the crisp one.

In fuzzy control one uses fuzzy inference systems $[33,34]$ which are based on fuzzy rules where a fuzzy conditional part (i.e premise part) is linked with a fuzzy conditional part, (i.e. consequent part) by If-Then terms. If a consequent part of a fuzzy rule is fuzzy, i.e. it represents a fuzzy set, then a procedure is needed, in the course of which to a fuzzy set or a fuzzy number a real number is attached. Such procedures are realized by functionals [35].

For fuzzy sets and convex fuzzy numbers we know a number of defuzzification procedures from the literature cf. $[2,34]$. In the case of fuzzy rules in which Ordered Fuzzy Numbers appear as their consequent parts we need to introduce a new defuzzification procedure. In this case the concept of functional, even linear, which maps elements of a Banach space into reals, will be useful.
Since the Banach space $\mathcal{R}=C([0,1]) \times C([0,1])$ the general representation of linear and continuous functional holds in the form [36]

$$
\phi(A)=\int_{0}^{1} f(s) d h_{1}(s)+\int_{0}^{1} g(s) d h_{2}(s),
$$

where $(f, g) \in \mathcal{R}$ represents an Ordered Fuzzy Number $A$, and $h_{1}, h_{2}$ are two functions of bounded variation on $[0,1]$.

In dealing with applications of fuzzy numbers we need set of functionals that map each fuzzy number into real, and in the consistent way with operations on reals. To be more strict we require some properties and introduce a particular class of functionals.

Definition 3. A map $\phi$ from the space $\mathcal{R}_{B V}$ of all OFN's to reals is called a defuzzification functional if is satisfies: 1) $\left.\phi\left(c^{\ddagger}\right)=c, 2\right) \phi\left(A+c^{\ddagger}\right)=\phi(A)+c$, 3) $\phi(c A)=c \phi(A)$, for any $c \in \mathbf{R}$ and $A \in \mathcal{R}$, where $c^{\ddagger}(s)=(c, c), s \in[0,1]$, represents a crisp number (a real number) $c \in \mathbf{R}$.

From this follow that each defuzzification functional must be homogeneous of order one, restrictive additive, and some how normalized.

Paraphrasing the probabilistic approach one can say that each defuzzification functional plays in the fuzzy number theory the role similar to the mean (expected) value in the probability. However, from the above formula an infinite number of defuzzification procedures can be defined.

Notice that each linear and bounded defuzzification functional on the space $\mathcal{R}$ is determined by a pair of functions of bounded variation $h_{1}, h_{2}$ satisfying the constraint

$$
\int_{0}^{1} d h_{1}(s)+\int_{0}^{1} d h_{2}(s)=1 .
$$

The classical defuzzification linear functionals, known for convex fuzzy numbers, such as MOM (middle of maximum), FOM (first of maximum), LOM (last of maximum) are given by specification of $h_{1}$ and $h_{2}$ in (9).

If we put $h_{1}(s)$ and $h_{2}(s)$ as $\lambda H(s)$ and $(1-$ $\lambda) H(s)$, respectively, where $0 \leq \lambda \leq 1$ and $H(s)$ is a step Heaviside'a (jump at $s=1$ ), then we obtain all classical defuzzification functionals: MOM ( middle of maximum), FOM (first of maximum), LOM (last of maximum) and RCOM (random choice of maximum) depending on $\lambda$. If, for example, we put $h_{1}(s)=h_{2}(s)=1 / 2 H(s)$, then we get MOM:

$$
\phi_{M O M}(f, g)=1 / 2(f(1)+g(1)) .
$$


To get FOM we have to put $h_{1}(s)=H(s)$ and $h_{2}(s)=0$, and to obtain LOM we need $h_{2}(s)=H(s)$ and $h_{1}(s)=0$.

From the above formula an infinite number of defuzzification procedures can be defined. One of defuzzification procedures in terms of an area under the membership relation can be defined, it is realized by a linear combinations of two Lebesgue measures of $[0,1]$. In the present case, however, the area is calculated in the $y$-variable.

An interesting class of functionals are those which are sensitive to orientation. We say that a defuzzification functional $\phi$ is sensitive to orientation (or shortly - orientation sensitive) if there exists a fuzzy number $(f, g) \in \mathcal{R}$ such that

$$
\phi(f, g) \neq \phi(g, f) .
$$

This class of functionals is recently discussed by Dobrosielski in [37].

It is obvious that neither COG nor MOM are orientation sensitive and two other are sensitive.

The next example of nonlinear defuzzification functional is defuzzification functional COG representing the center of gravity $[38-40] \phi_{G}$ calculated at OFN $A=(f, g)$ :

$$
\phi_{G}(f, g)=\frac{\int_{0}^{1} \frac{f(s)+g(s)}{2}|f(s)-g(s)| d s}{\int_{0}^{1}[f(s)-g(s)] d s} .
$$

If $A=c^{\ddagger}$ then we put $\phi_{G}\left(c^{\ddagger}\right)=c$. When $\int_{0}^{1} \mid f(s)-$ $g(s) \mid d s=0$ in (11) then we define

$$
\phi_{G}(f, f)=\left\{\int_{0}^{1} f(s) d s\right\}\left\{\int_{0}^{1} d s\right\}^{-1} .
$$

Another nonlinear defuzzification functional has been proposed by Wilczyńska in her diploma [41] cf. also [38, 39].

A relation of partial ordering in the space of all OFN, denoted by $\mathcal{R}$, can be introduced by defining the subset of 'positive' Ordered Fuzzy Numbers: a number $A=(f, g)$ is not less than zero, and by writing

$$
A \geq 0 \quad \text { iff } f \geq 0, g \geq 0 .
$$

In this way the set $\mathcal{R}$ becomes a partially ordered ring. The lattice structure can be also introduced [42].

\section{Step Ordered Fuzzy Numbers}

It is worthwhile to point out that a class of ordered fuzzy numbers (OFNs) will represent the whole class of convex fuzzy numbers if we do not require elements of each pair $(f, g)$ are continuous functions. Hence we are requiring, after [32], somehow less by introducing the next definition.

Definition 5. By an Ordered Fuzzy Number we understand a pair of functions $(f, g)$ defined on the unit interval $[0,1]$, which are functions of bounded variations.

The space of elements satisfying Def. 5 we will denote by $\mathcal{R}_{B V}$. All algebraic operations on $\mathcal{R}_{B V}$ are introduced in a similar way as by Def. 2 , and Eq. (8) with a small difference: now, in order to define $A \div B$, the functions $\left|f_{B}\right|$ and $\left|g_{B}\right|$ must be bounded from below.

Important consequence of this fact is the possibility of introducing a subspace of OFN composed of pairs of step functions. If we fix a natural number $K$ and split $[0,1)$ into $K-1$ subintervals $\left[a_{i}, a_{i+1}\right)$, i.e. $\bigcup_{i=1}^{K-1}\left[a_{i}, a_{i+1}\right)=[0,1)$, where $0=a_{1}<a_{2}<\ldots<$ $a_{K}=1$, and define a step function $f$ of resolution $K$ by putting $u_{i}$ on each subinterval $\left[a_{i}, a_{i+1}\right)$, then each such function $f$ is identified with a $K$-dimensional vector $f \sim \boldsymbol{u}=\left(u_{1}, u_{2} \ldots u_{K}\right) \in \mathbf{R}^{K}$, the $K$-th value $u_{K}$ corresponds to $s=1$, i.e. $f(1)=u_{K}$. Taking a pair of such functions we have an Ordered Fuzzy Number from $\mathcal{R}_{B V}$. Now we introduce.

Definition 6. By a Step Ordered Fuzzy Number $A$ of resolution $K$ we mean an ordered pair $(f, g)$ of functions such that $f, g:[0,1] \rightarrow \mathbf{R}$ are $K$-step functions.

We use $\mathcal{R}_{K}$ for denotation the set of elements satisfying Def. 5 and $\mathcal{R}_{K} \subset \mathcal{R}_{B V}$, of course. The example of a Step Ordered Fuzzy Number and its membership relation are shown in Fig. 7 .

The set $\mathcal{R}_{K} \subset \mathcal{R}_{B V}$ has been extensively elaborated by our students in [43] and [44]. We can identify $\mathcal{R}_{K}$ with the Cartesian product of $\mathbf{R}^{K} \times \mathbf{R}^{K}$ since each $K$-step function is represented by its $K$ values. It is obvious that each element of the space $\mathcal{R}_{K}$ may be regarded as an approximation of elements from $\mathcal{R}_{B V}$, by increasing the number $K$ of steps we are getting the better approximation. The norm of $\mathcal{R}_{K}$ is assumed to be the Euclidean one of $\mathbf{R}^{2 K}$, then we have a inner-product structure for our disposal.

In Fig. 3 two SOFNs, namely $A$ and $B$, and the result of their product are presented. 

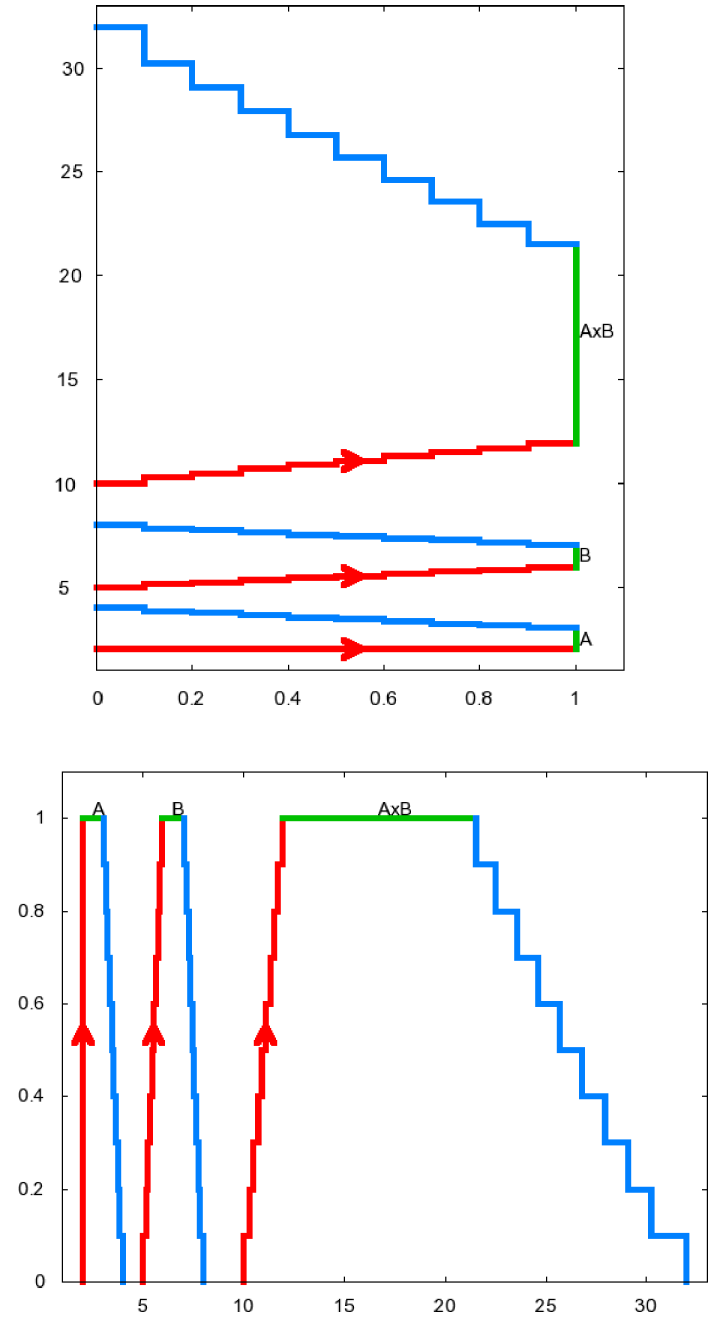

Fig. 3. Multiplication of two SOFNs $A$ and $B$ and corresponding membership relations.

\section{Interpretation}

The new model of fuzzy numbers makes possible to deal with fuzzy inputs quantitatively, exactly in the same way as with real numbers. Interesting thing is that the new interpretations supplied by the OFN model can be treated as an extend of classic proposals so we do not need abandon existing ideas to deal with new ones. Beside a little bit of different interpretation, the new model of fuzzy numbers has a lot of useful mathematical properties, in the particular we are getting rid of the main problem in a classical fuzzy numbers - the unbounded increase of inaccuracies with next calculations. Moreover, thanks to the new attempt we can define new methods based on the arithmetic of ordered fuzzy numbers of processing information in processes dealing with fuzzy control $[31,45]$.

In general, that is also a source of the idea of all fuzzy sets. Interpretation of the Ordered Fuzzy
Numbers is compatible with the general idea of the fuzzy sets. However, there exists a new property the orientation. By using OFNs we can describe any imprecise value in the real-life processes [46]. The parts up-branch and down-branch of OFN can be related to an opinion of an expert about dynamic changes of the analyzed value. The up-branch describes the behaviour of the value before the very moment when the opinion was made, and the downbranch describes value in afterwards. In that way we expand existing interpretation of fuzzy numbers. We can still use OFNs in the way as usual when we ignore the orientation, but we can also use the orientation to put more complex information about the evaluation made by OFNs. Let us look at the example in which we have an imprecise opinion "slow" about the speed of a vehicle as OFN $A$ (see Fig. 4). We can ignore the orientation and use this OFN as fuzzy data by saying speed 15 is surely slow and speeds 13 and 20 are slow in degree little more than $50 \%$. We can also take into consideration the orientation of OFN and can say: it is "slow in the speed-up process".

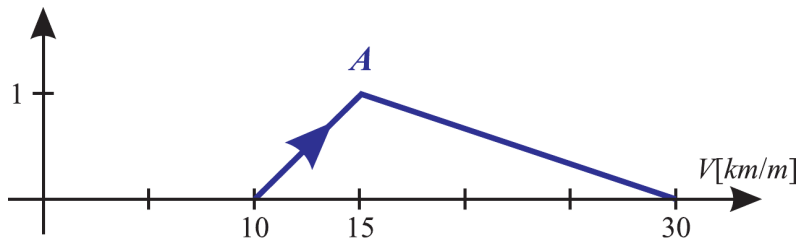

Fig. 4. An example of the OFNs describing "slow in speed-up process".

We have two OFNs where "wide" of branches (up and down) are different. Number $B$ is more "wide" than $A$. What does it mean? We can find answer if we make more deep (but simply) analysis. If the expert has made up-branch of $A$ from 5 to 4 millions then he considers possible range of changes as 1 million. Up-branch of $B$ was made from 1 to 3 millions so he considers range of changes as 2 millions. To sum up, we understand number $B$ as an information about more dynamic process than $A$. Another thing is the direction that shows that $A$ is a decreasing process and $B$ is an increasing one (see Fig. 5).
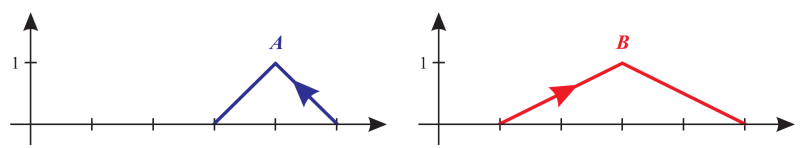

Fig. 5. An example of the OFNs that describes income in two units of financial company.

In real life we could expect total income of analyzed company about 7 millions. Additional, if the increasing process of $B$ was more dynamic than decreasing of $A$ then we expect in total also increas- 
ing process, however less dynamic than for $B$. If we use OFN model and add numbers $A$ and $B$ according to the definition then we get expected results (Fig. 6).

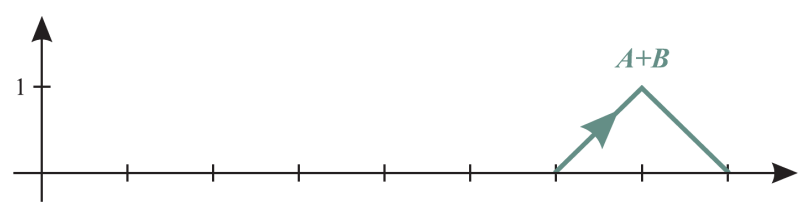

Fig. 6. The total income of company and sum of OFNs $A$ and $B$.

\section{Fuzzy cash flow and fuzzy IRR}

Since future returns are always uncertain one can modelled the net cash flow using positive Ordered Fuzzy Numbers, and try to solve Eq. (7) as a fuzzy equation. So one can look for ordered fuzzy number $X=\left(f_{r}, g_{r}\right) \in \mathcal{R}_{B V}$, which is a unique positive root of the fuzzy polynomial

$$
W(X):=\sum_{i=1}^{n-1} A_{i} X^{i}-A_{0},
$$

where all coefficients $A_{0}, A_{1}, \ldots, A_{n}$ are positive OFN's. The variable $X$ is related to the previous $r$ from (7) by the relation $X=\left(1^{\ddagger}+r\right)^{-1}$, where $1^{\ddagger}$ is the fuzzy representation of the crisp number 1 .

Notice that to one fuzzy polynomial (13) correspond two polynomials in the space $B V([0,1])$ of real-valued functions defined on $[0,1]$

$$
\begin{aligned}
W_{1}\left(f_{r}\right) & :=\sum_{i=1}^{n-1} f_{a i}\left(f_{r}\right)^{i}-f_{a 0}, \\
W_{2}\left(g_{r}\right) & :=\sum_{i=1}^{n-1} g_{a i}\left(g_{r}\right)^{i}-g_{a 0},
\end{aligned}
$$

where for each $i=0,1,2 \ldots, n-1$ we put $A_{i}=$ $\left(f_{a i}, g_{a i}\right) \in \mathcal{R}_{B V}$.

Remark: If the above assumptions concerning coefficients in (13) are satisfied then there exists a unique positive ordered fuzzy number $X_{r 0}=\left(f_{r 0}, g_{r 0}\right)$ which is the root of the polynomial $W(X)$, i.e. $W\left(X_{r 0}\right)=0^{\ddagger}$, where $0^{\ddagger}$ represents the crisp zero. In terms of (14) this can be written as

$$
\sum_{i=1}^{n-1} f_{a i}\left(f_{r 0}\right)^{i}=f_{a 0}, \quad \sum_{i=1}^{n-1} g_{a i}\left(g_{r 0}\right)^{i}=g_{a 0} .
$$

Such result cannot be, however, formulated working with classical fuzzy numbers and traditional fuzzy algebra and $\alpha$-cuts, cf. [1].

\section{Numerical example}

In our numerical example we are going to choose an investment project of duration $n=10$ years and Step Ordered Fuzzy Numbers of a fixed resolution $K=4$ as representatives of the cash flow. The starting year is 2010 and the last year of the simulation is 2019. The cash flow is determined for a fictitious firm.
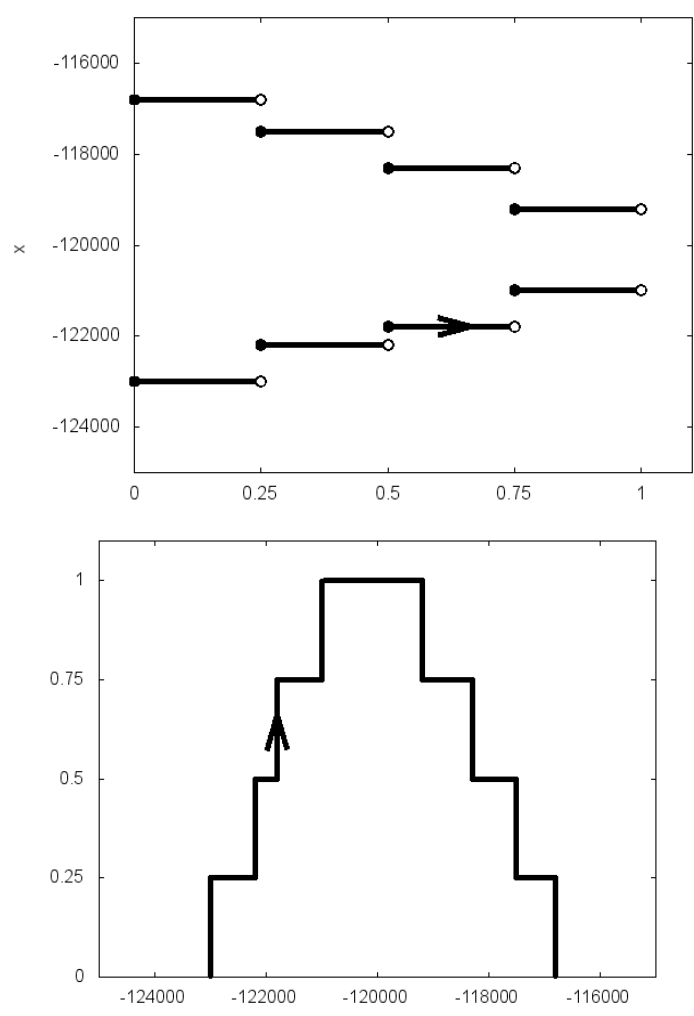

Fig. 7. Initial expenditure in 2010 as a step OFN in two representations: Ordered Fuzzy Number and its membership relation.

On the last Fig. 7 orientation of the number represents the trend of observed or anticipated fuzzy values of the flow. Here the orientation is called positive.

Basing on 10 fuzzy numbers 4 variants have been prepared, which differ by the orientations of particular flows. Let us put all in a compact form

1. Variant A: all numbers have positive orientation,

2. Variant B: negative fuzzy flow terms have negative orientation and positive ones have positive ones,

3. Variant C: all numbers have negative orientation,

4. Variant D: in the years 2010-2013 numbers have negative orientation, while in the years 2014-2015 numbers have positive orientation and since 2016 the orientation is negative.

Now we will present graphically some flow terms. 

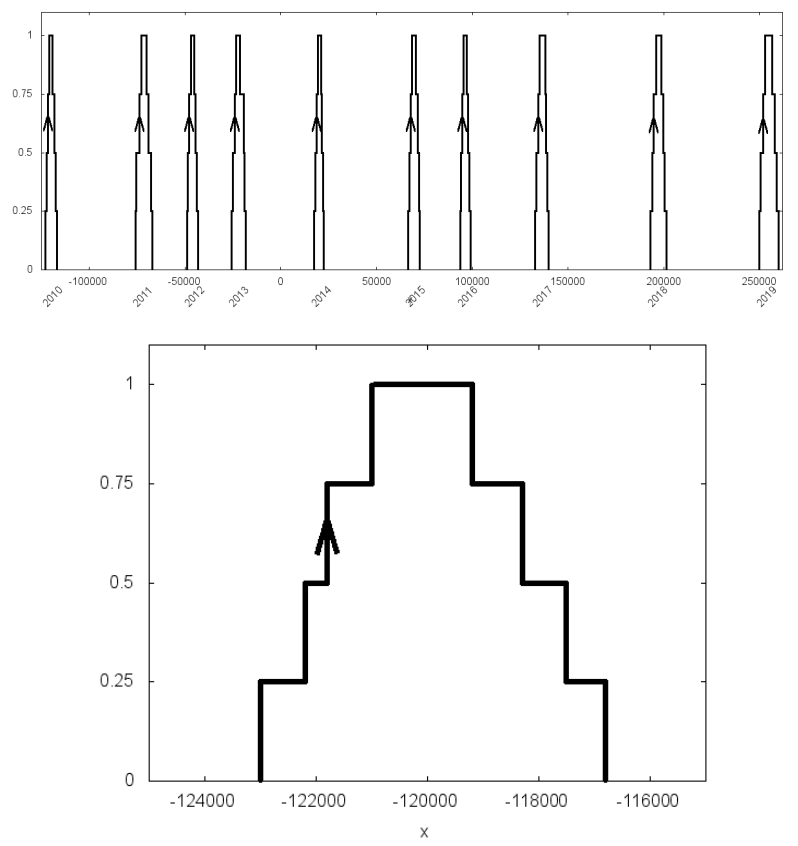

Fig. 8. Cash flow in Variant A, traditional representation as membership relations and the enlargement of the initial expenditure.

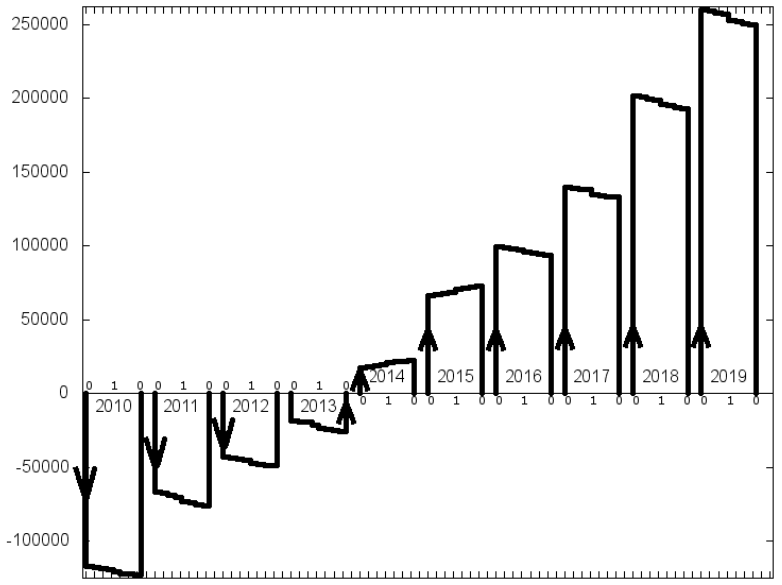

time

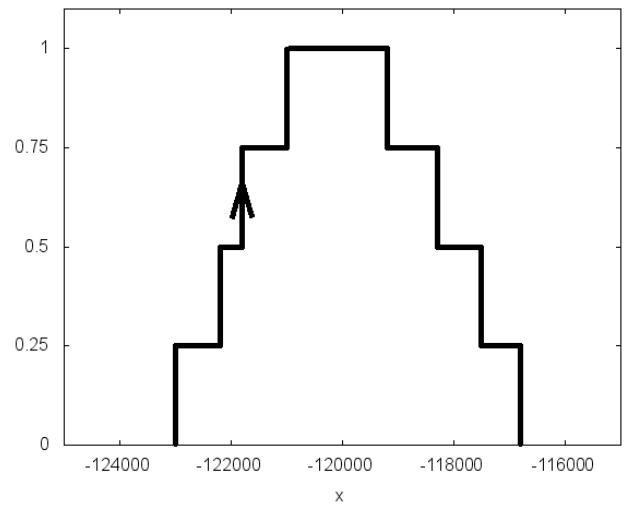

Fig. 9. Cash flows in Variant D, modified representation where the negative orientation of fuzzy numbers is represented as numbers below the main axis.
In Fig. 9 we have presented our flows as step OFN in the modified way: The negative orientation of fuzzy numbers have been represented as numbers below the main axis.

Now we are looking for the roots of our fuzzy polynomial (13) in which numerical values of its coefficients from our experiments. Then we determine fuzzy internal rate of return for all variants A till D. Here calculations for the cases D and $\mathrm{C}$ are given in the graphical form in Fig. 10.
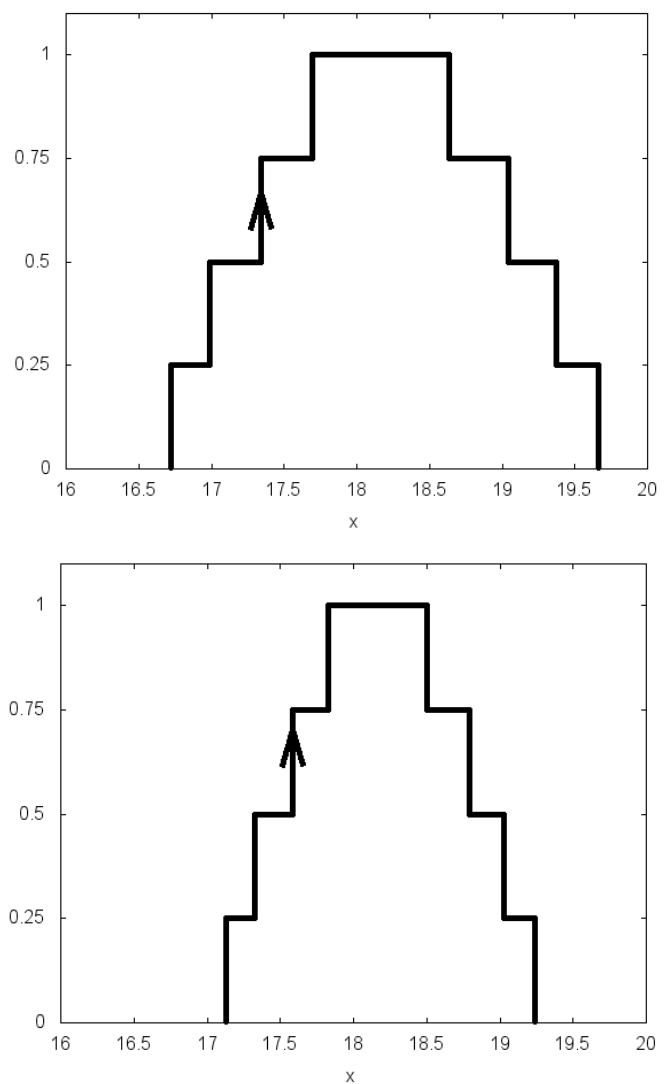

Fig. 10. Fuzzy internal rate of return for the variants C and D.

The space of OFNs is partially ordered by the relation (12), hence we may try to sort those determined fuzzy IRR. The result of the sorting supplies us a new tool for the constructed decision supporting system. Another tool will result from the application of some defuzzification functionals. We may apply 4 different functionals: COG - center of gravity and MOM - mean of maxima, which are nonsensitive to orientation, and two sensitive ones, namely LOM last of maxima and FOM - first of maxima. The defuzzification results are presented in Fig. 11.

Now in Table 1 we have gathered results of those 4 defuzzification operations. What we are observing it is a strong dependence on the variant, i.e. on the 
orientation of fuzzy cash flow. From those results we can deduce orientations of each fuzzy value of IRR. In the case of Variant A we can see that the orientation of those numbers is positive, while in Variants B, $\mathrm{C}$ and $\mathrm{D}$ the orientation is negative (cf. Fig. 11). Defuzzification by MOM of the fuzzy IRR in all variants gives almost the same results, while the defuzzification results by COG may be put into two groups: one group is composed of Variants A, C and D, and the second one - of Variant B.
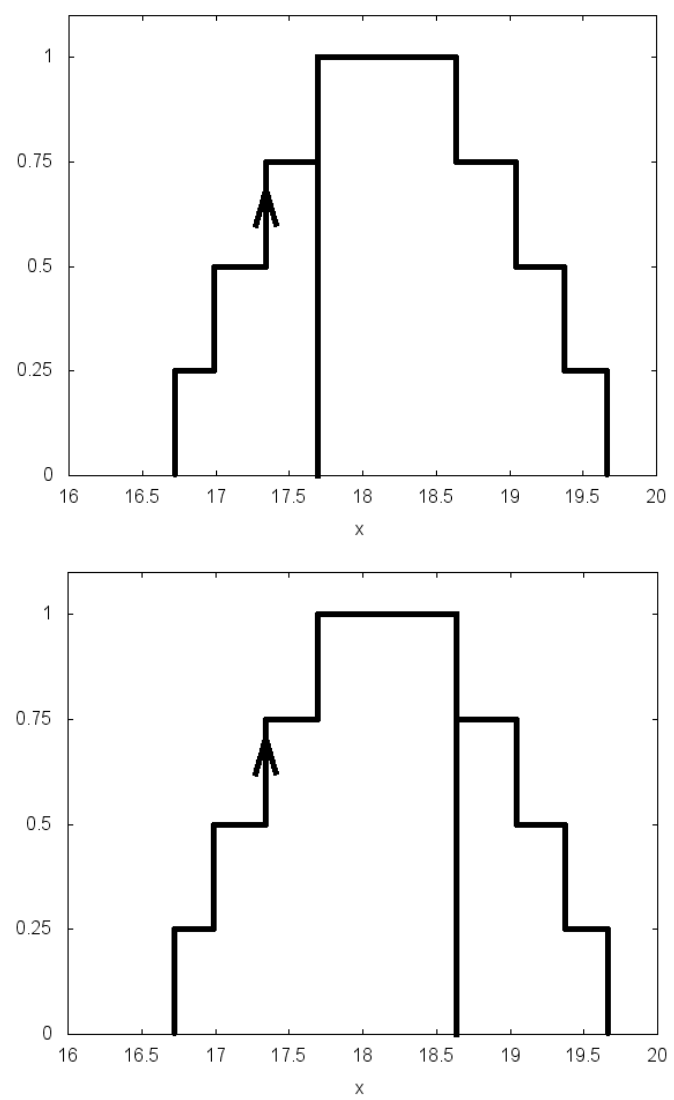

Fig. 11. Defuzzifications of IRR by LOM and FOM for the Variant C.

Table 1

Results of defuzzifications by LOM, FOM, MOM and COG for all variants.

\begin{tabular}{l|c|c|c|c}
\hline Variants & LOM & FOM & MOM & COG \\
\hline Variant A & 18.64 & 17.69 & 18.1656 & 18.1851 \\
\hline Variant B & 18.08 & 18.25 & 18.1644 & 18.1776 \\
\hline Variant C & 17.69 & 18.64 & 18.1656 & 18.1851 \\
\hline Variant D & 17.83 & 18.50 & 18.1650 & 18.1807 \\
\hline
\end{tabular}

\section{Conclusions}

We remember that the internal rate of return is the discount rate at which the net present value of an investment becomes zero, it means that it is the discount rate which equates the present value of the future cash flows of an investment with the initial investment. So it is one of the several measures used for investment appraisal. So it is a tool to measure and compare the profitability of investments. Then the decision rule is formulated as follows: An investment project should only be accepted if its IRR is not less than the target internal rate of return, $r_{c}$, say, or it is greater than an established minimum acceptable rate of return or cost of capital. When comparing two or more mutually exclusive projects, the project having highest value of IRR should be accepted.

In a scenario where an investment is considered by the firm that has equity holders, this minimum rate is the cost of capital of the investment (which may be determined by the risk-adjusted cost of capital of alternative investments). This ensures that the investment is supported by equity holders since, in general, an investment whose IRR exceeds its cost of capital adds value for the firm, i.e. it is economically profitable.

In cases where one project has a higher initial investment than a second mutually exclusive project, the first project may have a lower IRR (expected return), but a higher NPV (increase in shareholders' wealth) and should thus be accepted over the second project (assuming no capital constraints). Hence in such cases the calculated IRR should not be used to rate mutually exclusive projects, but only to decide whether a single project is worth investing in. Since IRR does not consider cost of capital, it should not be used to compare projects of different duration. Then we should use modified internal rate of return (MIRR) which does consider cost of capital and provides a better indication of a project's efficiency in contributing to the firm's discounted cash flow. This is more obvious in the case of an investment project in which positive cash flows are followed by negative ones and then by positive ones. Then we can face with multiple internal rates of return [47] Those remarks give some limitations on calculated IRR as an investment decision tool $[47,48]$.

\section{References}

[1] Buckley J.J., The fuzzy mathematics of finance, Fuzzy Sets and Systems, 21, 257-274, 1987.

[2] Chen Guanrong, Pham Trung Tat, Fuzzy Sets, Fuzzy Logic, and Fuzzy Control Systems, CRS Press, Boca Raton, London, New York, Washington, D.C., 2001.

[3] Buckley James J., Eslami E., An Introduction to Fuzzy Logic and Fuzzy Sets, Physica-Verlag, Springer-Verlag, Heidelberg, 2005. 
[4] Duboi D., Prade H., Operations on fuzzy numbers, Int. J. System Science, 9 (6), 613-626, 1978.

[5] Klir G.J., Fuzzy arithmetic with requisite constraints, Fuzzy Sets and Systems, 91, 165-175, 1997.

[6] Zadeh L.A., Fuzzy sets, Information and Control, 8, 338-353, 1965.

[7] Zadeh L.A., The concept of a linguistic variable and its application to approximate reasoning, Part I, Information Sciences, 8, 199-249, 1975.

[8] Buckley J.J., Solving fuzzy equations in economics and finance, Fuzzy Sets and Systems, 48, 289-296, 1992.

[9] Kosiński W., On soft computing and modelling, Image Processing Communications, An International Journal with special section: Technologies of Data Transmission and Processing, held in 5th International Conference INTERPOR 2006, 11 (1), 71-82, 2006 .

[10] Chwastyk A., Kosiński W., Fuzzy calculus with applications [in Polish: Rachunek rozmyty z aplikacja$m i$ ], Matematyka Stosowana, 15/56, 2013, in print.

[11] Dobija M., Administrating Accounting and Controlling [in Polish: Rachnkowość Zarzadcza i Controlling], Wydawnictwo Naukowe PWN, Warszawa, 1999.

[12] Jarugowa A., Nowak W.A., Szychta A., Administrating Accounting [in Polish: Rachunkowość Zarzadcza], Absolwent, Gdańsk, 1999.

[13] Nahotko S., Efectiveness and risc in innovation processes [in Polish: Efektywność i ryzyko w procesach innowacyjnych], TNOiK, Bydgoszcz, 1999.

[14] Ju Y.J., Kim C.E., Shim J.-C., Genetic-based fuzzy models: interest rate forecasting problem, Computers and Industrial Engineering, 33 (3-4), 561-564, 1997.

[15] Kingham M., Mohammadia M., Financial modelling and prediction of interest rate using fuzzy logic and genetic algorithms, in: Proceed. of the 1996 Australina-New Zeland Conf., on Intelligent Information Systems, IEEE, New York, pp. 233-266, 1996.

[16] Kuchta D., A step towards fuzzy accounting, Badania Operacyjne i Decyzje, 1, 75-84, 2000.

[17] Kosiński W., Prokopowicz P., Ślęzak D., Fuzzy numbers with algebraic operations: algorithmic approach, in: Intelligent Information Systems 2002, M. Kłopotek, S.T. Wierzchoń, M. Michalewicz [Eds.], Proc. IIS'2002, Sopot, June 3-6, 2002, Poland, Physica Verlag, pp. 311-320, 2002.
[18] Kosiński W., Prokopowicz P., D. Ślęzak, Drawback of fuzzy arithmetics - new intutions and propositions, in: Proc. Methods of Aritificial Intelligence, T. Burczyński, W. Cholewa, W. Moczulski [Eds.], PACM, Gliwice, Poland, 2002, pp. 231-237, 2002.

[19] Kosiński W., Prokopowicz P., Ślęzak D., On algebraic operations on fuzzy numbers, in: Intelligent Information Processing and Web Mining, Proc. of the International IIS: IIPWM'03 Conference held in Zakopane, Poland, June 2-5, 2003), M. Kłopotek, S.T. Wierzchoń, K. Trojanowski [Eds.], Physica Verlag, Heidelberg, pp. 353-362, 2003.

[20] Kosiński W., Prokopowicz P., Ślȩzak D., Ordered fuzzy numbers. Bulletin of the Polish Academy of Sciences, Sér. Sci. Math., 51 (3), 327-338, 2003.

[21] Kosiński W., Prokopowicz P., Algebra of fuzzy numbers [in Polish: Algebra liczb rozmytych], Matematyka Stosowana, 5/46, 37-63, 2004.

[22] Kosiński W., Prokopowicz P., Ślęzak D., Calculus with fuzzy numbers in: Proc. Intern. Workshop on Intelligent Media for Communicative Intelligence, Warszawa, September, 2004, L.Bolc, T. Nishida, Z. Michalewicz,(eds), LNCS, vol. 3490, pp. 21-28 Springer, Heidelberg, (2005).

[23] Kuchta D., Soft Mathematics in Managament. Application of interval and fuzzy numbers in administrating accounting [in Polish: Miȩkka matematyka $w$ zarzadzaniu. Zastosowanie liczb przedziałowych $i$ rozmytych $w$ rachunkowości zarzadczej], Oficyna Wydawnicza Politechniki Wrocławskiej, Wrocław, 2001.

[24] Koleśnik R., Kosiński W., Prokopowicz P., Frischmuth K., On algebra of ordered fuzzy numbers, in: Soft Computing - Foundations and Theoretical Aspects, K.T. Atanassov, O. Hryniewicz, J. Kacprzyk [Eds.], Akademicka Oficyna Wydawnicza EXIT, Warszawa, pp. 291-302, (2004).

[25] Nguyen H.T.. A note on the extension principle for fuzzy sets, J. Math. Anal. Appl., 64, 369-380, 1978.

[26] Goetschel R. Jr., Voxman W., Elementary fuzzy calculus, Fuzzy Sets and Systems, 18 (1), 31-43, 1986.

[27] Kaucher E., Interval analysis in the extended interval space IR, Computing Suppl., 2, 33-49, 1989.

[28] Drewniak J., Fuzzy numbers [in Polish], in: Fuzzy Sets and their Applications, Zbiory rozmyte $i$ ich $z a-$ stosowania, Chojcan J., Łȩski J. [Eds.], WPŚ, Gliwice, Poland, pp. 103-129, 2001.

[29] Wagenknecht M., On the approximate treatment of fuzzy arithmetics by inclusion, linear regression and information content estimation, in: Fuzzy Sets and their Applications, Zbiory rozmyte $i$ ich zastosowa- 
nia, Chojcan J. Łȩski J. [Eds.], Wydawnictwo Politechniki Ślạskiej, Gliwice, pp. 291-310, 2001.

[30] Kaufman A., Gupta M.M., Introduction to Fuzzy Arithmetic, Van Nostrand Reinhold, New York, 1991.

[31] Prokopowcz P., Algoritmization of operations on fuzzy numbers and its applications [in Polish: Algorytmizacja dziatań na liczbach rozmytych i jej zastosowania], Ph.D. Thesis, IPPT PAN, Warszawa, 2005.

[32] Kosiński W., On fuzzy number calculus, Int. J. Appl. Math. Comput. Sci., 16 (1), 51-57, 2006.

[33] Czogała E., Pedrycz W., Elements and methods of fuzzy set theory [in Polish], PWN, Warszawa, 1985.

[34] Piegat A., Fuzzy modelling and control [in Polish: Modelowanie i sterowanie rozmyte], Akademicka Oficyna Wydawnicza EXIT, Warszawa, 1999.

[35] Kosiński W., On defuzzyfication of ordered fuzzy numbers, in: Artifical Intelligence and Soft Computing ICAISC 2004, Proc. of the 7th Intern. Conf. Zakopane, Poland, June 2004, Rutkowski L., Siekmann J., Tadeusiewicz R., Zadeh L.A. [Eds.], Springer, Berlin, pp. 326-333, 2004.

[36] Alexiewicz A., Functional Analysis [in Polish: Analiza funkcjonala], PWN, Warszawa, 1969.

[37] Dobrosielski W., Trangular extension - new defuzzification methods of Ordered Fuzzy Numbers [in Polish: Trójkatne Rozszerzanie, nowa metoda wyostrzania na skierowanych liczbach rozmytych], in: Proceedings of XIV International PhD Workshop OWD 2012, Conference Archives, PTETiS, 31, 328-333, 2012.

[38] Kosiński W., Piasecki W., Wilczyńska-Sztyma D., On fuzzy rules and defuzzification functionals for Ordered Fuzzy Numbers, in: Proc. of AIMeth'2009 Conference, Nowvember, 2009, Burczyński T., Cholewa W., Moczulski W. [Eds.] AIMETH Series, pp. 161-178, Gliwice, 2009.

[39] Kosiński W., Wilczyńska-Sztyma D., Defuzzification and implication within ordered fuzzy numbers, in: WCCI 2010 IEEE World Congress on Computational Intelligence July, 18-23, 2010 - CCIB, Barcelona, Spain, pp. 1073-1079, 2010.
[40] Rosa A., Modelling with Ordered Fuzzy Numbers [in Polish: Modelowanie z wykorzystaniem skierownych liczb rozmytych], Engineering Thesis, WMFiT, Kazimierz-Wielki University, Bydgoszcz, 2011.

[41] Wilczyńska D., On control aspects within ordered fuzzy numbers in MATLAB environment [in Polish], Master Thesis, WMFiT, Kazimierz-Wielki University, Bydgoszcz, 2007.

[42] Kacprzak M., Kosiński W., On lattice structure and implications on ordered fuzzy numbers, In: Proc. of the 7th Conference of the European Society for Fuzzy Logic and Technology, EUSFLAT, Aix-lesBains, France, July 18-22, 2011, Galichet Sylvie, Montero Javier, Mauris Gilles [Eds.], Atlantis Press, ISBN 978-90-78677-00-0, pp. 267-274, 2011.

[43] Gruszczyńska A., Krajewska I., Fuzzy Calculator on Step Ordered Fuzzy Numbers [in Polish], Engineering Thesis, WMFiT, Kazimierz-Wielki University, Bydgoszcz, 2008.

[44] Kościeński K., Modul of Step Ordered Fuzzy Numbers in Control of Material Point Motion [in Polish: Modut schodkowych skierowanych liczb rozmytych $w$ sterowaniu ruchem punktu materialnego], Engineering Thesis, PJWSTK, Warszawa, 2010.

[45] Prokopowicz P., Using ordered fuzzy numbers arithmetic, in: Fuzzy Control in Artificial Intelligence and Soft Computing, Proc. of the 8th International Conference on Artificial Intelligence and Soft Computing Zakopane, Polska, 2004, June 25-29, 2006, Cader A., Rutkowski L., Tadeusiewicz R., Zurada J. [Eds.], Academic Publishing House EXIT, Warsaw, pp. 156-162, 2006.

[46] Kosiński W., Prokopowicz P., Kacprzak D., Fuzziness - representation of dynamic changes by ordered fuzzy numbers, Chapter in: Views of Fuzzy Sets and Systems from Different Perspectives, Rudolf Seising [Ed.], Studies in Fuzziness and Soft Computing, Vol. 243, Springer, Berlin,Heidelberg, pp. 485-508, 2009 .

[47] Hazen G.B., A new perspective on multiple internal rates of return, The Engineering Economist, 48 (2), 31-51, 2003.

[48] Hartman J.C., Schafrick I.C., (2004), The relevant internal rate of return, The Engineering Economist, 49 (2), 139-158. 